\title{
Robert Carachi, Jay L. Grosfeld, Amir F. Azmy (eds) The Surgery of Childhood Tumors, 2nd corrected and enlarged edition
}

\author{
Springer, 2008, XXVI, 626 pp., 505 illus., 157 in colour, hardcover, \\ ISBN 978-3-540-29733-8
}

\author{
Martin T. Corbally
}

Published online: 24 January 2009

(C) Springer-Verlag 2009

The recent publication of "The Surgery of Childhood Tumors" by Carachi, Grosfeld and Azmy is a most welcome addition to the literature detailing the surgical aspects of childhood tumours. There are few publications in this area and the authors have put together an excellent book with an impressive input from a variety of world-renowned experts.

Arranged broadly in three sections, with the first section dealing mainly with tumour biology, imaging, chemotherapy, radiotherapy and genetics and subsequent chapters based on specific clinical areas, the book finishes with chapters on supportive and palliative care and new treatments. Often overlooked in our approach to the child and family with a "surgical" malignancy, these areas are dealt with comprehensively and will provide useful guidance to the specialist surgical oncologist or the paediatric surgeon involved in cancer management in children.

In addition to chapters on liver, renal and soft tissue sarcoma there are sections on rare paediatric tumours and second malignancies post treatment. The book is complemented with excellent imaging and clinical photographs, many in colour. Chapters begin with an index of contents and a description of presentation, pathology and tumour genetics, staging, biopsy techniques, treatment and complications.

The book fills a void, is well written, and will provide a comprehensive reference for all those involved in this difficult but rewarding area. 